\title{
HbA1c is Positively Associated with Serum Carcinoembryonic Antigen (CEA) in Patients with Diabetes: A Cross-Sectional Study
}

\author{
Jun Lu $\cdot$ Hongtao Wang $\cdot$ Xueli Zhang $\cdot$ Xuemei Yu
}

Received: September 19, 2017 / Published online: January 4, 2018

(C) The Author(s) 2018. This article is an open access publication

\section{ABSTRACT}

Introduction: To explore the influence of glycemic levels on the serum carcinoembryonic antigen (CEA) levels in patients with diabetes.

Methods: This is a cross-sectional study. Patients with diabetes aged 18-75 years old were recruited. Those patients with carcinoma, abnormal renal function (serum creatinine $\geq 115 \mu \mathrm{mol} / \mathrm{l}$ ), and abnormal hepatic function (serum alanine aminotransferase $\geq 97.5 \mathrm{U} / \mathrm{l}$ ) were excluded in this study. Blood samples were obtained from every patient after an overnight fasting, and CEA was determined using a chemiluminescent particle immunoassay.

Results: A total of 324 patients with type 1 diabetes and 3019 patients with type 2 diabetes

Enhanced content To view enhanced content for this article go to http://www.medengine.com/Redeem/ 490DF060618AAB25.

J. Lu $\cdot$ H. Wang $\cdot$ X. Yu $(\bowtie)$

Department of Endocrinology and Metabolism, Shanghai University of Medicine and Health Sciences Affiliated Fengxian Hospital, Shanghai, China

e-mail: xuemeiyu12@163.com

J. Lu $\cdot$ H. Wang $\cdot$ X. Zhang $(\bowtie) \cdot X$. Yu

Department of Comprehensive Diagnosis and Treatment for Diabetes, Shanghai University of Medicine and Health Sciences Affiliated Fengxian Hospital, Shanghai, China e-mail: lejing1996@aliyun.com were included in this study. Patients with type 1 diabetes had higher levels of HbA1c $(9.5 \%$ vs. $8.7 \%$ ) and CEA (2.79 vs. $2.34 \mathrm{ng} / \mathrm{ml}$ ), but lower fasting $C$ peptide $(0.72$ vs. $1.71 \mathrm{ng} / \mathrm{ml})$ than those with type 2 diabetes (all $P<0.001$ ). Data indicated that CEA was higher in patients with smoking, drinking, older age, higher levels of HbA1c, and lower level of fasting $\mathrm{C}$ peptide (all $P<0.05)$. Multiple linear regression analysis indicated that CEA was independently associated with smoking, age, BMI, and HbA1c (all $P<0.05)$.

Conclusion: HbA1c was positively associated with the levels of CEA in patients with diabetes. More studies are warranted to investigate whether elevated CEA is associated with increased carcinoma risk in patients with diabetes.

Keywords: Carcinoembryonic antigen;

Diabetes; Glycosylated hemoglobin

\section{INTRODUCTION}

Carcinoembryonic antigen (CEA) has been always used as a tumor marker for diagnosis and predicting the prognosis of carcinoma of the colorectum, lung, thyroid, etc. [1-3]. CEA was monitored in patients with carcinoma in order to judge the disease process and give clues to recurrence in those under radical resection [4-6]. Moreover, elevated CEA levels were also found in patients with carcinoma of the 
stomach, liver, lung, pancreas, breast, ovary, uterus/cervix uteri, and urinary organs [5, 7-12]. CEA may also increase in such pathological conditions as hepatic cirrhosis/inflammation, pulmonary emphysema, rectal polyps, and colon inflammation [13, 14].

Diabetes, especially type 2 diabetes, was associated with increased risk incidence of carcinoma. A prospective study in China indicated that patients with type 2 diabetes mellitus were associated with higher incidence and mortality risks of cancer, especially pancreatic cancer, in comparison to the general population [15]. The Veteran Administration Registry Study also reported an increasing incidence of pancreatic carcinoma in patients with type 2 diabetes in comparison to the non-diabetic controls [16]. It has also been reported that uncontrolled severe hyperglycemia rather than preoperative diabetes mellitus negatively affects the survival outcomes following pancreatic ductal adenocarcinoma (PDAC) resection [17]. However, the level of CEA was not investigated in this study despite higher levels of CEA being recognized as a tumor marker in these tumors.

Several studies indicated that the status of diabetes affects serous levels of markers of carcinoma. The level of CA 19-9 has been explored in various studies; it was increased in patients with type 2 diabetes and highly correlated with glycemic control [18-20]. CEA has also been reported to be associated with hyperglycemia in patients with diabetes in small-scale studies $[19,20]$. However, the influence of glycemic control on the levels of CEA was scarcely investigated in large-scale samples. In this study, we intended to investigate the factors affecting the level of CEA in Chinese patients with diabetes.

\section{METHODS}

\section{Subjects}

This study was launched from March 2012 to December 2016 and performed at the Department of Endocrinology and Metabolism, Shanghai University of Medicine and Health Sciences Affiliated Fengxian Hospital in
Shanghai, China. The inclusion criteria included age between 18 and 75; with complete clinical data. Those patients with malignancy $(n=8)$, renal dysfunction (serum creatinine $\geq 115 \mu \mathrm{mol} / \mathrm{l}, \quad n=111$ ), and abnormal hepatic function (serum alanine aminotransferase $\geq 97.5 \mathrm{U} / \mathrm{l}, \quad n=64$ ) were excluded according to the study protocol. In total, 3343 patients with diabetes aged 18-75 years were included in this study. Data on demographic information and clinical parameters were collected via patients' records.

All procedures followed were in accordance with the ethical standards of the responsible committee on human experimentation (institutional and national) and with the Helsinki Declaration of 1964, as revised in 2013. This study was approved by the Shanghai University of Medicine and Health Sciences Affiliated Fengxian Hospital institutional review board. All patients gave written informed consent prior to data collection.

\section{Anthropometric and Biochemical Measurements}

Body mass index (BMI) was assessed with the formula as follows: BMI $\left(\mathrm{kg} / \mathrm{m}^{2}\right)=$ body weight $(\mathrm{kg}) /$ height squared $\left(\mathrm{m}^{2}\right)$. Height and weight were measured according to the standard protocol.

Subjects fasted overnight for at least $10 \mathrm{~h}$ before venous blood samples were drawn. Parameters such as glycosylated hemoglobin (HbA1c), fasting plasma glucose (FPG), lipid profiles, and fasting $\mathrm{C}$ peptide (FCP) were determined with the methods as previously described [21]. CEA was determined using a chemiluminescent particle immunoassay (ARCHITECT, Abbott Ireland Diagnostics Division, Sligo, Ireland).

\section{Definition of Diabetes Types}

The World Health Organization (WHO) report (1999) defined diabetes as FPG $\geq 7.0 \mathrm{mmol} / \mathrm{l}$ and/or a 2-h post-load plasma glucose $(2 \mathrm{hPG}) \geq 11.1 \mathrm{mmol} / \mathrm{l}$, or being on medical treatment for diabetes [22]. Type 1 diabetes 
Table 1 Comparison of clinical characteristics in patients with various CEA levels

\begin{tabular}{|c|c|c|c|}
\hline Variables & Type 1 diabetes $(n=324)$ & Type 2 diabetes $(n=3019)$ & $P$ value \\
\hline Gender (men) & $167(51.5)$ & $1859(61.6)$ & 0.001 \\
\hline Current smoker (\%) & $23(23.5)$ & $577(28.0)$ & 0.327 \\
\hline Current drinker (\%) & $11(11.2)$ & $268(13.0)$ & 0.607 \\
\hline Age (years) & $55(45-62)$ & $56(49-64)$ & 0.012 \\
\hline Duration of diabetes (years) & $3(1-8)$ & $6(1-10)$ & $<0.001$ \\
\hline BMI $\left(\mathrm{kg} / \mathrm{m}^{2}\right)$ & $22.0(20.1-24.4)$ & $24.5(22.2-26.8)$ & $<0.001$ \\
\hline Systolic blood pressure $(\mathrm{mmHg})$ & $120(110-135)$ & $130(120-140)$ & $<0.001$ \\
\hline Diastolic blood pressure $(\mathrm{mmHg})$ & $80(70-83.75)$ & $80(72-85)$ & $<0.001$ \\
\hline HbAlc (\%) & $9.5(7.6-11.6)$ & $8.7(7.2-10.7)$ & $<0.001$ \\
\hline FPG $(\mathrm{mmol} / \mathrm{l})$ & $8.24(6.06-10.99)$ & $7.84(6.32-10.16)$ & 0.448 \\
\hline $\mathrm{FCP}(\mathrm{ng} / \mathrm{ml})$ & $0.72(0.22-1.65)$ & $1.71(1.03-2.45)$ & $<0.001$ \\
\hline $\mathrm{TC}(\mathrm{mmol} / \mathrm{l})$ & $4.70(4.00-5.32)$ & $4.64(3.99-5.34)$ & 0.788 \\
\hline $\mathrm{TG}(\mathrm{mmol} / \mathrm{l})$ & $1.02(0.72-1.54)$ & $1.44(0.99-2.15)$ & $<0.001$ \\
\hline HDL-C (mmol/l) & $1.20(0.99-1.50)$ & $1.06(0.90-1.27)$ & $<0.001$ \\
\hline LDL-C (mmol/l) & $2.95(2.37-3.60)$ & $3.00(2.42-3.65)$ & 0.439 \\
\hline SCr (umol/l) & $60(50-72)$ & $65(54-76)$ & $<0.001$ \\
\hline $\operatorname{ALT}(\mathrm{U} / \mathrm{l})$ & $17(12-27)$ & $20(14-30)$ & $<0.001$ \\
\hline $\operatorname{AST}(\mathrm{U} / \mathrm{l})$ & $18(15-23)$ & $19(15-24)$ & 0.276 \\
\hline $\mathrm{CEA}(\mathrm{ng} / \mathrm{ml})$ & $2.79(1.86-4.02)$ & $2.34(1.62-3.42)$ & $<0.001$ \\
\hline
\end{tabular}

Data are median (interquartile range, IQR) or number (\%). $P$ values between two groups were calculated using Mann-Whitney test for continuous variables or Chi square test for categorical variables

$A L T$ alanine aminotransferase, $A S T$ aspartate aminotransferase, $B M I$ body mass index, $C E A$ carcinoembryonic antigen, $F P G$, fasting plasma glucose, $H b A l c$ glycosylated hemoglobin, $T C$ total cholesterol, $T G$ triglyceride, $H D L-C$ high density lipoprotein-cholesterol, $L D L-C$ low density lipoprotein-cholesterol, $F C P$ fasting $\mathrm{C}$ peptide, $S C r$ serum creatinine

mellitus and type 2 diabetes mellitus were identified according to the criteria established by the American Diabetes Association (2010) [23]. Insulin deficiency was defined as FCP $<0.9 \mathrm{ng} / \mathrm{ml}$.

\section{Statistical Analysis}

Continuous variables were presented as median (interquartile range, IQR), and categorical variables as number (percentage). Differences in medians were assessed using the Mann-Whitney
$U$ test between two groups and the Kruskal-Wallis test among three or four groups; differences in proportions were analyzed using the Chi square test. The correlation between CEA and clinical characteristics was tested using multiple linear regression analysis by backward step method. The age/HbA1c-fitted CEA levels were calculated using Stata software, all other statistical analyses were performed using SPSS 19.0 (SPSS Inc., Chicago, IL, USA); two-sided $P$ values less than 0.05 were considered statistically significant. 
Table 2 Comparison of clinical characteristics in patients with various CEA levels

\begin{tabular}{|c|c|c|c|c|c|}
\hline Variables & Q1 $(n=835)$ & $\mathrm{Q} 2(n=827)$ & Q3 $(n=844)$ & $\mathrm{Q} 4(n=837)$ & $P$ value \\
\hline Gender (men) & $415(49.7)$ & $474(57.3)$ & $544(64.5)$ & $593(70.8)$ & $<0.001$ \\
\hline Current smoker (\%) & $98(17.6)$ & $126(23.7)$ & $160(29.5)$ & $216(41.1)$ & $<0.001$ \\
\hline Current drinker (\%) & $57(10.2)$ & $48(9)$ & $88(16.2)$ & $86(16.4)$ & $<0.001$ \\
\hline Age (years) & $54(46-61)$ & $56(48-63)$ & $56(50-64)$ & $58(51-65)$ & $<0.001$ \\
\hline Duration of diabetes (years) & $5(1-10)$ & $6(1-10)$ & $5(1-10)$ & $5(1-10)$ & 0.013 \\
\hline BMI $\left(\mathrm{kg} / \mathrm{m}^{2}\right)$ & $24.6(22.2-26.8)$ & $24.3(22.2-26.8)$ & $24.1(21.8-26.8)$ & $23.9(21.5-26.2)$ & 0.004 \\
\hline $\begin{array}{l}\text { Systolic blood pressure } \\
\qquad(\mathrm{mmHg})\end{array}$ & $130(120-140)$ & $130(120-140)$ & $130(120-140)$ & $130(120-140)$ & 0.329 \\
\hline $\begin{array}{l}\text { Diastolic blood pressure } \\
\quad(\mathrm{mmHg})\end{array}$ & $80(70-85)$ & $80(72-85)$ & $80(70-86)$ & $80(70-85)$ & 0.782 \\
\hline HbAlc (\%) & $7.8(6.7-9.2)$ & $8.5(7.0-10.4)$ & $9.1(7.5-11.0)$ & $10.1(8.1-12.0)$ & $<0.001$ \\
\hline FPG $(\mathrm{mmol} / \mathrm{l})$ & $7.24(6.00-8.83)$ & $7.68(6.30-10.16)$ & $8.15(6.50-10.50)$ & $8.57(6.68-11.47)$ & $<0.001$ \\
\hline $\mathrm{FCP}(\mathrm{ng} / \mathrm{ml})$ & $1.84(1.23-2.58)$ & $1.78(1.10-2.54)$ & $1.57(0.85-2.37)$ & $1.31(0.67-2.08)$ & $<0.001$ \\
\hline $\mathrm{TC}(\mathrm{mmol} / \mathrm{l})$ & $4.50(3.88-5.22)$ & $4.70(4.00-5.40)$ & $4.65(4.01-5.37)$ & $4.73(4.06-5.40)$ & $<0.001$ \\
\hline TG $(\mathrm{mmol} / \mathrm{l})$ & $1.45(0.97-2.11)$ & $1.47(1.05-2.20)$ & $1.37(0.93-2.12)$ & $1.32(0.89-1.99)$ & $<0.001$ \\
\hline HDL-C $(\mathrm{mmol} / \mathrm{l})$ & $1.05(0.90-1.25)$ & $1.06(0.90-1.27)$ & $1.08(0.90-1.29)$ & $1.09(0.90-1.33)$ & 0.007 \\
\hline LDL-C (mmol/l) & $2.96(2.30-3.52)$ & $3.06(2.50-3.72)$ & $2.96(2.40-3.63)$ & $3.00(2.50-3.71)$ & 0.022 \\
\hline SCr $($ umol/l) & $61(51-72)$ & $64(53-74)$ & $65(55-77)$ & $66(56-78)$ & $<0.001$ \\
\hline $\operatorname{ALT}(\mathrm{U} / \mathrm{l})$ & $19(13-30)$ & $19(14-30)$ & $20(14-30)$ & $19(13-30)$ & 0.587 \\
\hline AST (U/l) & $18(15-24)$ & $18(15-24)$ & $19(15-24)$ & $19(15-25)$ & 0.445 \\
\hline
\end{tabular}

Data were median (interquartile range, IQR) or number (\%). $P$ values among four groups were calculated using Kruskal-Wallis test for continuous variables or Chi square test for categorical variables

\section{RESULTS}

\section{Clinical Characteristics of the Patients}

As shown in Table 1, patients with type 1 diabetes had shorter duration of diabetes, but higher levels of HbA1c, high density lipoprotein-cholesterol (HDL-C) and CEA, but lower BMI, FCP, alanine aminotransferase (ALT), and triglyceride (TG). Table 2 shows the clinical characteristics in patients with different CEA quartiles. There were significant differences in gender composition, proportion of current smoker and drinker, age, duration of diabetes,
BMI, and levels of HbA1c, FCP, FPG, total cholesterol (TC), TG, HDL-C, and low density lipoprotein-cholesterol (LDL-C) among the four CEA quartiles (all $P$ values for trend $<0.05$ ). There were no significant differences in systolic blood pressure, diastolic blood pressure, ALT, and aspartate aminotransferase (AST).

\section{Levels of CEA in Different Subgroups}

Also, the levels of CEA in different subgroups were also investigated in our study (Fig. 1). Data indicated that men, current smokers, current drinkers, the elderly, and patients with insulin 

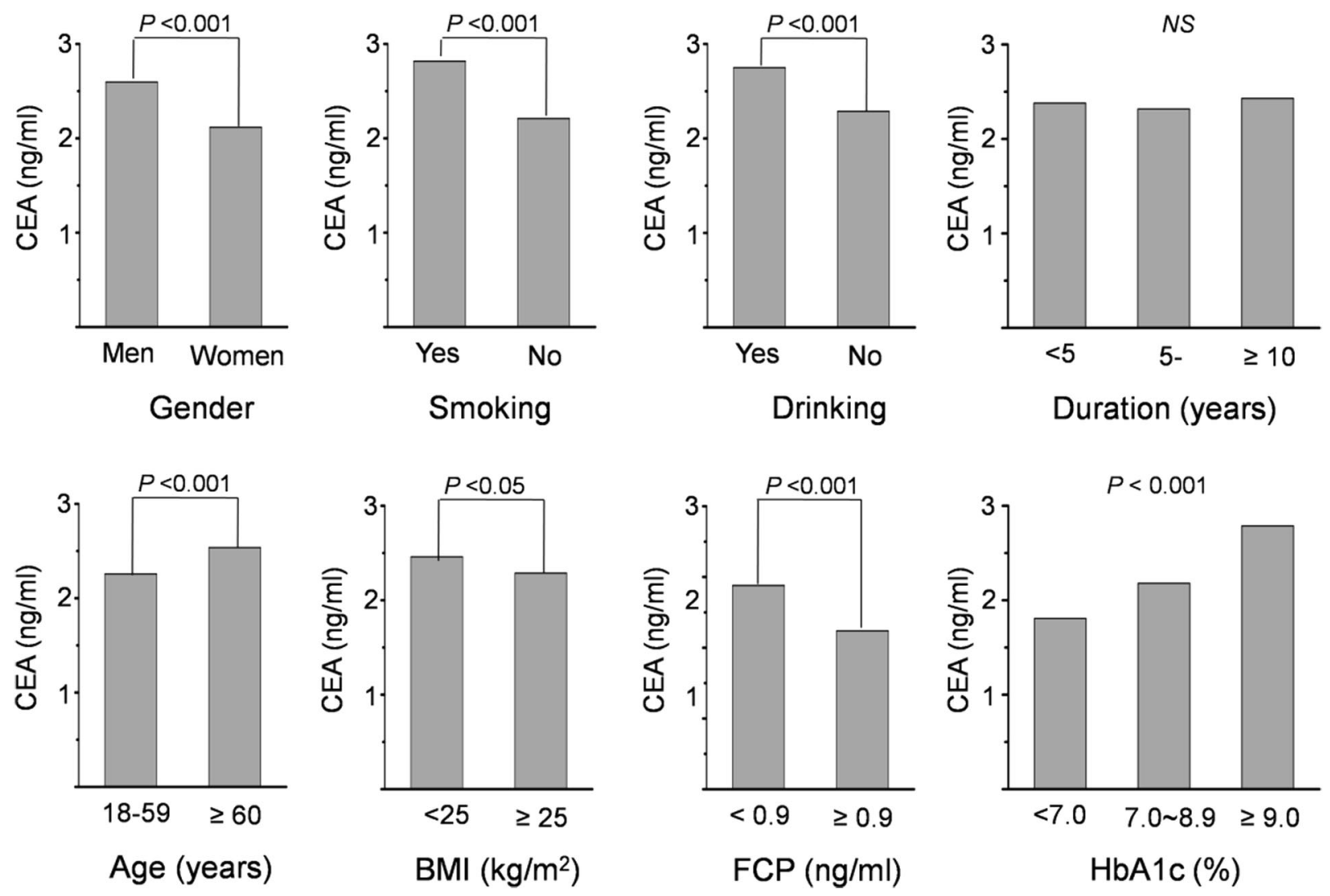

Fig. 1 Levels of CEA in different subgroups. $B M I$ body mass index, $C E A$ carcinoembryonic antigen, $F C P$ fasting $C$ peptide, HbAlc glycosylated hemoglobin

deficiency had higher CEA levels than their counterparts $(P<0.001)$. Individuals with type 1 diabetes had higher CEA than those with type

Table 3 Clinical indices related to CEA

\begin{tabular}{|c|c|c|c|c|}
\hline Variables & $B$ & $\begin{array}{l}\text { Standard } \\
\text { deviation }\end{array}$ & $t$ & $P$ value \\
\hline $\begin{array}{c}\text { Current } \\
\text { smoker } \\
\text { (yes) }\end{array}$ & 0.708 & 0.352 & 2.009 & 0.045 \\
\hline Age (years) & 0.038 & 0.014 & 2.665 & 0.008 \\
\hline $\begin{array}{c}\text { BMI }(\mathrm{kg} / \\
\left.\mathrm{m}^{2}\right)\end{array}$ & -0.086 & 0.043 & -2.004 & 0.045 \\
\hline HbAlc (\%) & 0.163 & 0.068 & 2.400 & 0.016 \\
\hline (Constant) & 1.325 & 1.599 & 0.829 & 0.407 \\
\hline
\end{tabular}

Data were analyzed using multiple linear regression by backward method, adjusted for drinking status, gender, duration of diabetes, diabetes types, TC, HDL-C, and FCP
2 diabetes. Moreover, data indicated that levels of CEA were different among patients with different $\mathrm{HbA1c}$ intervals grouped by HbA1c $<7 \%$, $7.0-8.9 \%$, and $\geq 9.0 \% \quad(P$ value for trend $<0.001)$. There was no significant difference in CEA levels among patients with different diabetes duration. However, overweight/ obesity subjects had lower CEA levels than those with normal weight $(P<0.05)$.

\section{Clinical Parameters Related to CEA Level}

Multiple linear regression analysis indicated that variables such as current smoking, age, $\mathrm{BMI}$, and HbA1c were independently correlated with CEA levels (all $P<0.05$, shown in Table 3). Simultaneously, the linear association between age/HbA1c and CEA was fitted, controlling the influence of confounder factors such as drinking status, gender, diabetes duration, FCP, BMI, TG, and HDL-C (Fig. 2). The respective 


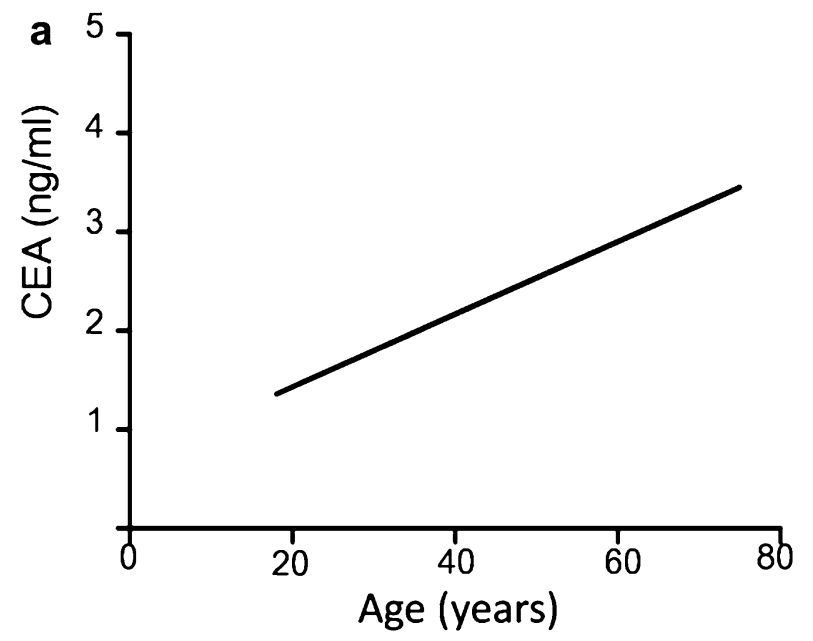

Fig. 2 Association of CEA with age (a) and HbAlc (b). The respective linear regression equations were $Y=0.037 X+0.7$, and $Y=0.175 X+1.37$ (all $P$ values $<0.001$ ), where $X$ is age (years) or HbAlc (\%) and $Y$ is

equations of CEA (ng/ml) with age (years) and HbA1c (\%) were $Y=0.037 X+0.7$, and $Y=0.175 X+1.37$ (all $P$ values $<0.001$ ).

\section{DISCUSSION}

In this study, we reported an intimate correlation of CEA with clinical parameters such as current smoking, age, BMI, and HbA1c in patients with diabetes.

Tobacco smoking has been reported to associated with increased cancer incidence and mortality [24]. In this study, data indicated a higher level of CEA in current smokers.

The elderly have a higher incidence of cancer due to impaired immune function [25]. Aging was also reported to be associated with elevated CEA early in 1976 [26], and positive association between age and CEA has also been observed in current study. Our previous study demonstrated that BMI was positively associated with FCP, and overweight/obesity subjects had better glycemic control [27], which may explain the lower levels of CEA in those with overweight/ obesity in comparison with normal weight individuals.

Elevated CEA levels in patients with pancreatic cancer have been reported to be associated

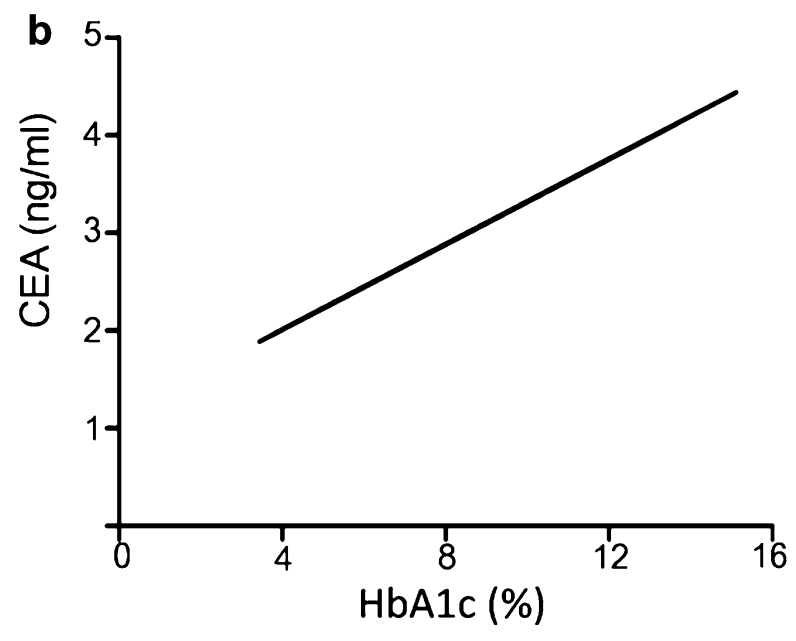

CEA level (ng/ml). Data were adjusted for drinking status, gender, diabetes duration, FCP, BMI, TG, and HDL-C

with onset of diabetes [28]. It has also been reported that patients with diabetes have elevated levels of tumor-related markers, such as CA 19-9, CA125, CA153, in previous studies $[9,18]$. It has been demonstrated that glycemic levels were positively associated with tumor markers such as CA 19-9 [18]. In this study, we report a positive relationship between HbA1c and CEA. The mechanism behind this phenomenon was unclear. Chronic inflammation is associated with insulin resistance and the onset of diabetes. It was reported that patients with diabetes had increased inflammatory molecules such as C-reactive protein (CRP), adiponectin, interleukin-6, and adhesion molecules such as soluble E-selectin, ICAM-1, etc. [29-32]. On the other hand, chronic inflammation induced the metabolic reprogramming associated with tumorigenesis of colorectal cancer [33]. It has also been reported that hyperglycemia may modulate the activity of the rate-limiting enzyme, glutamine:fructose-6-phosphate amidotransferase (GFAT), resulting in an increase of hexosamine biosynthetic pathway (HBP) activity and increased cell proliferation, invasion, and tumor progression of colon cancer [34]. These phenomena may partially explain elevated CEA levels in individuals with poor glycemic control. 
However, there are some limitations in this study. Firstly, this was a cross-sectional study, it is unknown if this intimate relationship between HbA1c and CEA means a higher risk of carcinoma incidence, and more studies are warranted to investigate whether elevated CEA is associated with increased carcinoma risk in patients with diabetes. Secondly, the mechanism of the influence of HbA1c on CEA needs more experimental studies; this was not investigated here. Finally, subjects with normal glycemic status were not included as a control group in this study.

\section{CONCLUSION}

HbA1c is positively correlated with CEA in patients with diabetes. We should be scrupulous in interpreting the results of CEA in patients with diabetes, especially in those with poor glycemic control.

\section{ACKNOWLEDGEMENTS}

Funding. This study and the article processing charges were funded by grants from Science and Technology Committee of Fengxian Area in Shanghai (20161001), the Shanghai Municipal Health and Family Planning Commission (20154Y0088), and Shanghai key disciplines.

Authorship. All named authors meet the International Committee of Medical Journal Editors (ICMJE) criteria for authorship for this manuscript, take responsibility for the integrity of the work as a whole, and have given final approval for the version to be published.

Author Contributions. Jun $\mathrm{Lu}$ performed the statistical analysis and wrote the manuscript; Hongtao Wang collected data, Xueli Zhang and Xuemei Yu participated in the design of this study and edited the manuscript.

Disclosures. Jun Lu, Hongtao Wang, Xueli Zhang, and Xuemei $\mathrm{Yu}$ have nothing to disclose.
Compliance with Ethics Guidelines. All procedures followed were in accordance with the ethical standards of the responsible committee on human experimentation (institutional and national) and with the Helsinki Declaration of 1964, as revised in 2013. This study was approved by the Shanghai University of Medicine \& Health Sciences Affiliated Fengxian Hospital institutional review board. All patients gave written informed consent prior to data collection.

Data Availability. The datasets generated and/or analyzed during the current study are available from the corresponding author on reasonable request.

Open Access. This article is distributed under the terms of the Creative Commons Attribution-NonCommercial 4.0 International License (http://creativecommons.org/licenses/ by-nc/4.0/), which permits any noncommercial use, distribution, and reproduction in any medium, provided you give appropriate credit to the original author(s) and the source, provide a link to the Creative Commons license, and indicate if changes were made.

\section{REFERENCES}

1. Holdenrieder S. Biomarkers along the continuum of care in lung cancer. Scand J Clin Lab Investig Suppl. 2016;245:S40-5.

2. Barak V, Meirovitz A, Leibovici V, et al. The diagnostic and prognostic value of tumor markers (CEA, SCC, CYFRA 21-1, TPS) in head and neck cancer patients. Anticancer Res. 2015;35:5519-24.

3. Wang YR, Yan JX, Wang LN. The diagnostic value of serum carcino-embryonic antigen, alpha fetoprotein and carbohydrate antigen 19-9 for colorectal cancer. J Cancer Res Ther. 2014;10(Suppl):307-9.

4. Tomita M, Ayabe T, Chosa E, et al. Prognostic significance of a tumor marker index based on preoperative serum carcinoembryonic antigen and Krebs von den Lungen-6 levels in non-small cell lung cancer. Asian Pac J Cancer Prev. 2017;18:287-91. 
5. Polat E, Duman U, Duman M, et al. Diagnostic value of preoperative serum carcinoembryonic antigen and carbohydrate antigen 19-9 in colorectal cancer. Curr Oncol. 2014;21:e1-7.

6. Ozawa H, Kotake K, Hosaka M, et al. Incorporation of serum carcinoembryonic antigen levels into the prognostic grouping system of colon cancer. Int J Colorectal Dis. 2017;32(6):821-9.

7. Grunnet M, Sorensen JB. Carcinoembryonic antigen (CEA) as tumor marker in lung cancer. Lung Cancer. 2012;76:138-43.

8. Tsang JY, Kwok YK, Chan KW, et al. Expression and clinical significance of carcinoembryonic antigenrelated cell adhesion molecule 6 in breast cancers. Breast Cancer Res Treat. 2013;142:311-22.

9. $\mathrm{Fu} \mathrm{Y,} \mathrm{Li} \mathrm{H.} \mathrm{Assessing} \mathrm{clinical} \mathrm{significance} \mathrm{of} \mathrm{serum}$ CA15-3 and carcinoembryonic antigen (CEA) levels in breast cancer patients: a meta-analysis. Med Sci Monit. 2016;22:3154-62.

10. Wada N, Kurokawa Y, Miyazaki Y, et al. The characteristics of the serum carcinoembryonic antigen and carbohydrate antigen 19-9 levels in gastric cancer cases. Surg Today. 2017;47:227-32.

11. Yoshikawa M, Morine Y, Ikemoto T, et al. Elevated preoperative serum CEA level is associated with poor prognosis in patients with hepatocellular carcinoma through the epithelial-mesenchymal transition. Anticancer Res. 2017;37:1169-75.

12. Hashiguchi Y, Kasai M, Fukuda T, et al. Serum carcinoembryonic antigen as a tumour marker in patients with endometrial cancer. Curr Oncol. 2016;23:e439-42.

13. Mittal A, Farooqui SM, Pyrtuh S, et al. Efficacy of carcinogenic embryonic antigen in differential diagnosis of diseases of pancreas and liver-a comparative study in a tertiary care hospital of Western Nepal. Asian Pac J Cancer Prev. 2012;13:275-7.

14. Yoon $\mathrm{H}$, Kim $\mathrm{MH}$, Won $\mathrm{SH}$, et al. A comparative study on serum immunoglobulin and tumor marker levels in the patients with autoimmune pancreatitis and pancreatobiliary malignancies. Korean J Gastroenterol. 2013;61:327-32.

15. Gu Y, Hou X, Zheng Y, et al. Incidence and mortality risks of cancer in patients with type 2 diabetes: a retrospective study in Shanghai, China. Int J Environ Res Public Health. 2016;13(6):559.

16. Makhoul I, Yacoub A, Siegel E. Type 2 diabetes mellitus is associated with increased risk of pancreatic cancer: a veteran administration registry study. SAGE Open Med. 2016;4:2050312116682257.
17. Lee W, Yoon YS, Han HS, et al. Prognostic relevance of preoperative diabetes mellitus and the degree of hyperglycemia on the outcomes of resected pancreatic ductal adenocarcinoma. J Surg Oncol. 2016;113:203-8.

18. Yu H, Li R, Zhang L, et al. Serum CA19-9 level associated with metabolic control and pancreatic beta cell function in diabetic patients. Exp Diabetes Res. 2012;2012:745189.

19. Shang X, Song C, Du X, et al. The serum levels of tumor marker CA19-9, CEA, CA72-4, and NSE in type 2 diabetes without malignancy and the relations to the metabolic control. Saudi Med J. 2017;38:204-8.

20. Ata N, Dal K, Kucukazman M, et al. The effect of glycemic control on CEA, CA 19-9, amylase and lipase levels. Open Med. 2015;10:8-13.

21. Lu J, Gu Y, Guo M, et al. Serum magnesium concentration is inversely associated with albuminuria and retinopathy among patients with diabetes. J Diabetes Res. 2016;2016:1260141.

22. Definition, diagnosis and classification of diabetes mellitus and its complications. Report of a WHO consultation, Part 1: diagnosis and classification of diabetes mellitus. Geneva: World Health Organization; 1999.

23. American Diabetes A. Diagnosis and classification of diabetes mellitus. Diabetes Care. 2010;33(Suppl 1):S62-9.

24. Park S, Jee SH, Shin HR, et al. Attributable fraction of tobacco smoking on cancer using populationbased nationwide cancer incidence and mortality data in Korea. BMC Cancer. 2014;14:406.

25. Jackaman C, Tomay F, Duong L, et al. Aging and cancer: the role of macrophages and neutrophils. Ageing Res Rev. 2017;36:105-16.

26. Alexander JC, Silverman NA, Chretien PB. Effect of age and cigarette smoking on carcinoembryonic antigen levels. JAMA. 1976;235:1975-9.

27. Lu J, Hou X, Zhang L, et al. Association between body mass index and diabetic retinopathy in Chinese patients with type 2 diabetes. Acta Diabetol. 2015;52:701-8.

28. Guo Q, Kang M, Zhang B, et al. Elevated levels of CA 19-9 and CEA in pancreatic cancer-associated diabetes. J Cancer Res Clin Oncol. 2010;136:1627-31.

29. Pham MN, Hawa MI, Roden $M$, et al. Increased serum concentrations of adhesion molecules but not of chemokines in patients with type 2 diabetes 
compared with patients with type 1 diabetes and latent autoimmune diabetes in adult age: action LADA 5. Diabet Med. 2012;29:470-8.

30. Pham MN, Hawa MI, Pfleger C, et al. Pro- and antiinflammatory cytokines in latent autoimmune diabetes in adults, type 1 and type 2 diabetes patients: action LADA 4. Diabetologia. 2011;54:1630-8.

31. Xiang Y, Zhou P, Li X, et al. Heterogeneity of altered cytokine levels across the clinical spectrum of diabetes in China. Diabetes Care. 2011;34:1639-41.
32. Salman ZK, Refaat R, Selima E, et al. The combined effect of metformin and L-cysteine on inflammation, oxidative stress and insulin resistance in streptozotocin-induced type 2 diabetes in rats. Eur J Pharmacol. 2013;714:448-55.

33. Qu D, Shen L, Liu S, et al. Chronic inflammation confers to the metabolic reprogramming associated with tumorigenesis of colorectal cancer. Cancer Biol Ther. 2017;18:237-44.

34. Vasconcelos-Dos-Santos A, Loponte HF, Mantuano $\mathrm{NR}$, et al. Hyperglycemia exacerbates colon cancer malignancy through hexosamine biosynthetic pathway. Oncogenesis. 2017;6:e306. 